$\mathbf{R}_{\text {ESEarch }} \mathbf{P}_{\text {APER }} \longrightarrow \frac{\text { FOOD SCIENCE }}{\text { RESEARCH JOURNAL }}$

e ISSN-2230-9403 — Visit us : www.researchjournal.co.in Volume 7 | Issue 2 | October, 2016 | 234-238 DOI : $10.15740 / \mathrm{HAS} / \mathrm{FSRJ} / 7.2 / 234-238$

\title{
Effect of utilization of (Galactomannan) guar gum blended with acacia gum in yoghurt
}

\author{
B.A. JADHAV AND V.S. PAWAR
}

\begin{abstract}
The effect of guar and acacia gum blend at different concentrations viz., 0.1, 0.2, 0.4 and 0.6 per cent on the physicochemical, sensory properties and rheology of yogurt were studied. It was observed that the setting time of the yoghurt reduced with increased concentration of blend gum. The viscosity of samples containing blend gum increased compared to the control sample. As increase in levels of blend gum, the per cent synersis was noticed in decreased trend. No marked change in $\mathrm{pH}$ and acidity of yoghurt was recorded irrespective added of blend gum and their concentration. As level of blend gum concentration increased the total solid content was found increased. Sensory evaluation showed that the use of blend gum upto 0.2 per cent concentration improved body and texture of the product. Being hydrocolloid nature the blend gum improved the consistency and reduced whey separation in yoghurt.
\end{abstract}

Key Words : Acacia, Blend, Guar, Viscosity, Yoghurt

How to cite this article : Jadhav, B.A. and Pawar, V.S. (2016). Effect of utilization of (Galactomannan) guar gum blended with acacia gum in yoghurt. Food Sci. Res. J., 7(2): 234-238, DOI : 10.15740/HAS/FSRJ/7.2/234-238. 